\title{
Inspection of a Spherical Triple VLS-Grating for Self-Seeding of FLASH at DESY
}

\author{
Frank Siewert ${ }^{1}$, Heiner Lammert ${ }^{1}$, Gerd Reichardt ${ }^{1}$, Ulrich Hahn ${ }^{2}$, Rolf Treusch $^{2}$, \\ Ruben Reininger ${ }^{3}$ \\ ${ }^{1}$ BESSY mbH, Albert-Einstein-Straße. 15, 12489 Berlin, Germany, \\ ${ }^{2}$ DESY, Notkestraße 85, 22607 Hamburg, Germany, \\ ${ }^{3}$ Scientific Answers \& Solutions, 5708 Restal St., Madison, Ii 53711, USA
}

\begin{abstract}
To take benefit from the improved brilliance of the laser-like source, proposed beamlines at Free Electron Lasers (FEL) require optical elements of excellent precision, characterised by slope errors beyond the state of the art limit of $0.5 \mu \mathrm{rad}$ rms for plane and spherical shape. Part of the monochromator beamline for self-seeding at the vacuumultraviolet Free Electron Laser (FLASH) at DESY is a triple Variable Line Spacing (VLS) grating of spherical shape. The three grating structures on a common substrate will cover the wavelength range from 6.4 to $60 \mathrm{~nm}$. The challenging specifications of these grating structures are characterised by a slope error of less than $0.25 \mu \mathrm{rad}$ rms and very stringent parameters for the VLS-polynomial [1]. These grating structures have been measured by use of the Nano Optic Measuring Machine (NOM) at BESSY. Based on the principle of deflectometry the BESSY-NOM $[2,3]$ represents the latest generation of slope measuring metrology instruments. The NOM enables the inspection of optical components with a measurement uncertainty in the range of $0.05 \mu \mathrm{rad}$ rms. This is a five to tenfold improvement compared to state of the art metrology tools of today. Here it is demonstrated how these outstanding metrology capabilities have been applied for a sound characterisation of a challenging precision optical component with error limits five times below the specifications. In the shown example the grating's figure accuracy has been characterised by linescans and surface mapping measurements of the optical active sections. In additional measurements under Littrow condition the higher order diffraction signals of the laser pencil beam have been traced to measure the groove density variation of the different grating-structures with a lateral resolution of $1 \mathrm{~mm}$. In contrast to the sparse and point like measurements of the manufacturer, these high resolution measurements yield a "slope deviation equivalent" resulting from imperfections in the line density variation.
\end{abstract}

Keywords: Metrology, X-ray optics, FEL, NOM, VLS-grating.

PACS: 07.85. Qe

\section{INTRODUCTION}

The here described holographically recorded ion beam etched triple laminar Variable Line Spacing (VLS) grating of spherical shape is one of the key optical elements to be installed in the monochromator beamline for self seeding of the Free-Electron-LASer in Hamburg (FLASH) at DESY [2]. To guarantee an optimum beamline performance it is essential to inspect the three grating sections regarding their basic parameters: slope error, radius of curvature and groove density variation.

\section{THE NANO OPTIC MEASURING MACHINE - NOM}

The BESSY-NOM was used to inspect this high class grating. The NOM is a non-contact deflectometry metrology device developed to test reflecting free-form surfaces of up to a scan length of $1.2 \mathrm{~m}$. The NOM is a hybrid of two direct slope measuring sensors, a Long Trace Profiler (LTP) and an Auto Collimation Telescope (ACT) $[3,4]$. The minimum measurable local curvature is about $1 \mathrm{~m}$ for the LTP-head and about $10 \mathrm{~m}$ for the ACT. To validate the achieved measurement accuracy, the values obtained with the NOM have been crosschecked with other high precision metrology instruments like the ESAD method [5]. The NOM allows to measure optical

CP879, Synchrotron Radiation Instrumentation: Ninth International Conference, edited by Jae-Young Choi and Seungyu Rah

(C) 2007 American Institute of Physics 978-0-7354-0373-4/07/\$23.00 
components with an estimated measurement uncertainty in the range of $0.05 \mu \mathrm{rad} \mathrm{rms}[3,6]$. In general it is to consider that the uncertainty budget is to be estimated individually for each measurement.

\section{MEASUREMENTS AND RESULTS}

\section{Slope Measurements}

To obtain a first topography describing view of the grating, a 3D scan of the complete substrate has been taken, (see Fig. 1, a cutout of the LEG section is shown in Fig. 2). Based on these information line scans of the center line of the three grating sections and the spare section have been traced to inspect the slope error and the radius of curvature separately.
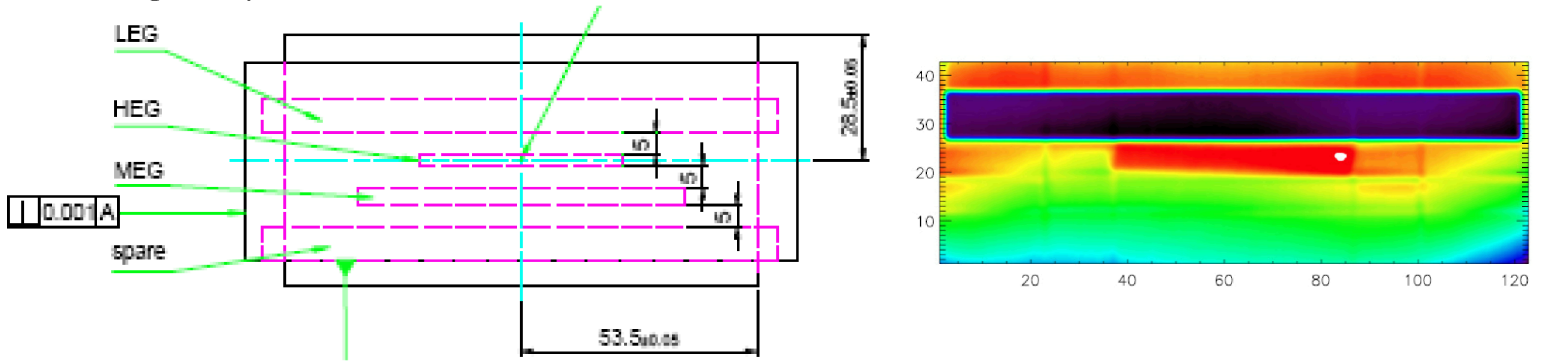

FIGURE 1. Scheme of the triple VLS-grating (left) and substrate topography achieved by 3D mapping at the NOM. The gratings are processed into silicon, the High- (HEG) and Mid Energy Grating (MEG) are coated with high density carbon.
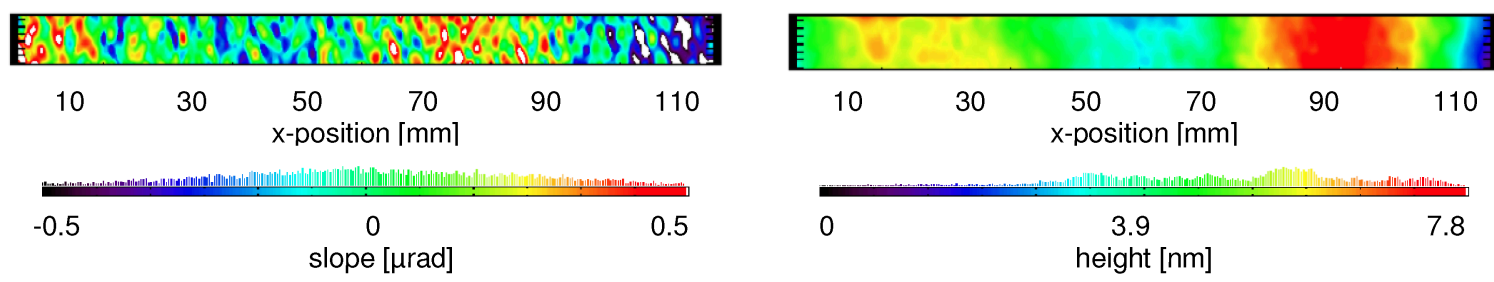

FIGURE 2. Low Energy Grating section, map of residual slope in meridional direction (left) and residual height (right).
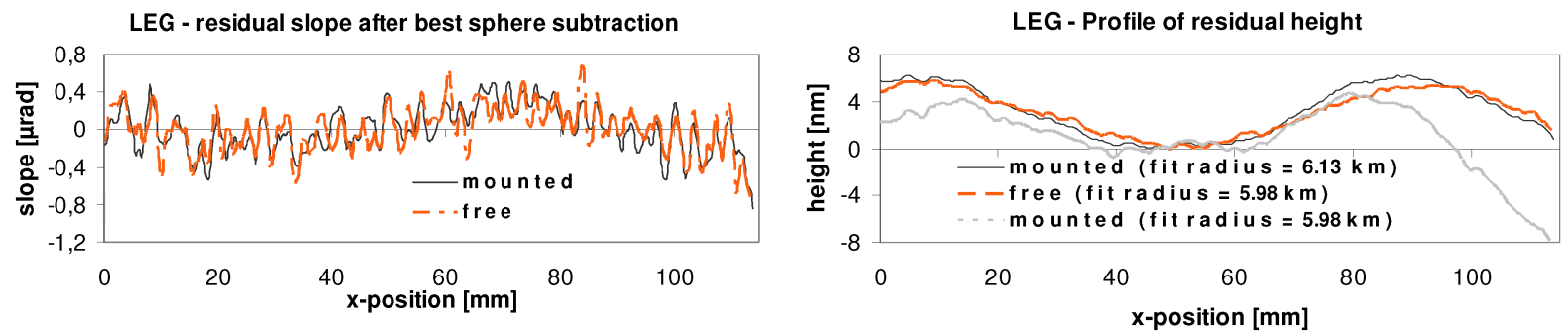

FIGURE 3. Low Energy Grating: residual slope (left) and height-profile (right) of center line - unmounted (dashed line) and mounted state.

The slope measurements were realized with the NOM-ACT. In the case of the HEG-section, an additional LTP-line scan was traced to cross check the achieved result (see Fig. 4). The three grating sections are characterized by excellent residual slope errors of $0.25 \mu \mathrm{rad} \mathrm{rms}$ and better. For the HEG-section of $45 \mathrm{~mm}$ in length a residual slope error of $0.13 \mu \mathrm{rad}$ rms has been measured. The conformity of the ACT and LTP measurement at the HEG is in the range of less than $0.2 \mathrm{~nm}$ rms for the "absolute" measured height data at center line (see Fig 4). Due to a worse signal to noise ratio caused by the grating structure, the estimated measurement uncertainty for the best fit slope error measured at the grating sections is about $0.1 \mu \mathrm{rad}$ rms. Nevertheless, this is five times superior compared to the required accuracy of the grating. The estimated uncertainty for the measurement at the spare section is about $0.05 \mu \mathrm{rad} \mathrm{rms}$. The differences in the achieved radius of curvature mainly results from the variation of scan length due to the length of the individual grating structure, covering different sections of the blank. In a final step line scan measurements of the mounted grating have been taken to exclude a possible distortion of shape caused by the 
mechanical supporting structure. The inspection of the mounted grating shows only slight changes of the shape (see Fig. 3). The residual slope is marginally modified in the range of some nanoradian and the radii of curvature change but remain within the specification (see Fig. 3 and Table. 1).
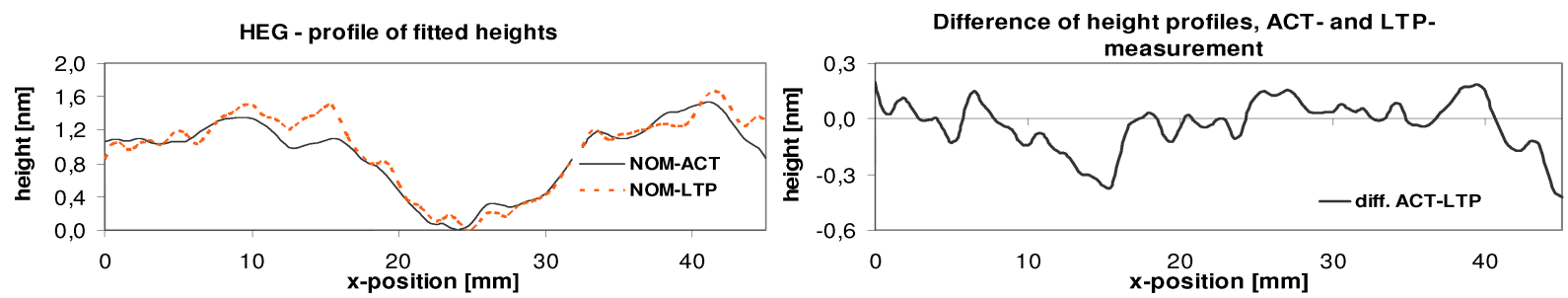

FIGURE 4. High Energy Grating: residual height-profile of center line (left side) and difference of residual height profile of NOM-LTP and ACT-measurement based on the same subtraction of circle fit for R $=5.87 \mathrm{~km}$.

TABLE 1. - shape characterizing data for unmounted and mounted state

\begin{tabular}{|c|c|c|c|c|c|}
\hline Parameter of inspection & Specification & Manufacturer & & BE & \\
\hline $\begin{array}{l}\text { Radius of curvature (long axis) } \\
{[\mathrm{km}]}\end{array}$ & $6.05 \pm 10 \%$ & 6.17 & $\begin{array}{l}\text { LEG: } \\
\text { HEG: } \\
\text { MEG: } \\
\text { Spare: }\end{array}$ & $\begin{array}{c}\text { unmounted } \\
5.98 \\
5.87 \\
5.85 \\
6.19\end{array}$ & $\begin{array}{c}\text { mounted } \\
6.13 \\
5.99 \\
5.98 \\
6.39\end{array}$ \\
\hline 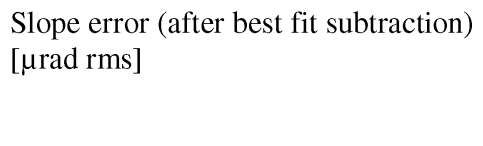 & $\leq 0.5$ & $\leq 0.26$ & $\begin{array}{l}\text { LEG: } \\
\text { HEG: } \\
\text { MEG: } \\
\text { Spare: }\end{array}$ & $\begin{array}{l}0.25 \\
0.13 \\
0.21 \\
0.23\end{array}$ & $\begin{array}{l}0.25 \\
0.15 \\
0.20 \\
0.21\end{array}$ \\
\hline
\end{tabular}

\section{Inspection of Groove Density}

The inspection of the groove density variation $(G)$ of an artificial periodic structure like a VLS-grating can be performed by use of a LTP taking the higher order signal of a diffracted laser beam $(\lambda=632.8 \mathrm{~nm}$ using a He-Nelaser) under Littrow condition. In this case incoming and diffracted higher order beam described by $\beta$ and $\alpha$ are in coincidence as shown in equation (1), with $n$ for the diffraction order used [6, 7].

$$
\beta=-\alpha \rightarrow 2 \sin (\alpha)=G n \lambda
$$

with

$$
G=k_{o}\left(1+2 b_{2} w+3 b_{3} w^{2}+3 b_{4} w^{3}\right)
$$

In the here discussed case of a spherical grating, the zero order slope profile of the substrate has been first measured by use of the NOM-LTP (like inspecting a mirror). To avoid an apparent groove density variation, the groove density describing data, sampled under Littrow condition, have to be corrected by the result of the zero order measurement [7]. To limit the influence of systematical errors, both the zero order and the Littrow measurements have been sampled in both directions from edge A to B and vice versa and than averaged. The line density variation of the grating structure can be described by a $3^{\text {rd }}$ order polynomial. The achieved result for the best fit polynomial is shown in Table. 2.
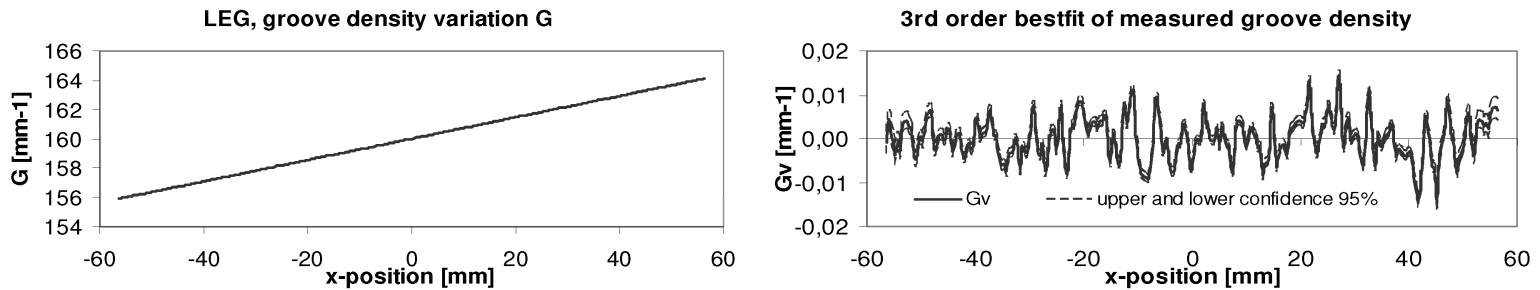

FIGURE 5. Low Energy Grating: profile of groove density variation (left) and $3^{\text {rd }}$ order best fit of groove density (right).

In all three cases the result is within the specification and in good compliance with the data of the manufacturer. 
Assuming a conservative estimation of the error budged for the LTP-head of about $0.5 \mu \mathrm{rad}$ rms the measurement uncertainty has been estimated (see Table. 2). Fig. 5 shows the result for the measured grove density variation of the LEG-section for a scan length of $115 \mathrm{~mm}$. The band of confidence for this measurement is expressed by the dashed lines.

TABLE 2. Result of groove density inspection

\begin{tabular}{|c|c|c|c|}
\hline Grating parameter: & Specification & Manufacturer & BESSY \\
\hline $\begin{array}{r}\text { LEG } \mathrm{k}_{0} \\
\mathrm{~b}_{2} \\
\mathrm{~b}_{3} \\
\mathrm{~b}_{4}\end{array}$ & $\begin{array}{c}160 \\
2.2795 \times 10^{-4} \\
<10^{-8} \\
<10^{-10}\end{array}$ & $\begin{array}{c}160.000 \\
2.2820 \times 10^{-4} \\
2.0069 \times 10^{-10} \\
6.0019 \times 10^{-11}\end{array}$ & $\begin{array}{c}160.007 \pm 4.8 \times 10^{-4} \\
2.2774 \times 10^{-4} \pm 7 \times 10^{-8} \\
1.3195 \times 10^{-9} \\
1.0603 \times 10^{-10}\end{array}$ \\
\hline $\begin{array}{r}\text { HEG } \mathrm{k}_{0} \\
\mathrm{~b}_{2} \\
\mathrm{~b}_{3} \\
\mathrm{~b}_{4}\end{array}$ & $\begin{array}{l}\quad 800 \\
2.2659 \times 10^{-4} \\
<10^{-8} \\
<10^{-10}\end{array}$ & $\begin{array}{c}799.995 \\
2.2656 \times 10^{-4} \\
7.9122 \times 10^{-10} \\
6.5621 \times 10^{-11}\end{array}$ & $\begin{array}{c}800.02 \pm 7.7 \times 10^{-4} \\
2.3192 \times 10^{-4} \pm 6 \times 10^{-8} \\
1.3245 \times 10^{-8} \\
5.0234 \times 10^{-10}\end{array}$ \\
\hline $\begin{array}{r}\text { MEG } \mathrm{k}_{0} \\
\mathrm{~b}_{2} \\
\mathrm{~b}_{3} \\
\mathrm{~b}_{4}\end{array}$ & $\begin{array}{c}356 \\
2.2750 \times 10^{-4} \\
<10^{-8} \\
<10^{-10}\end{array}$ & $\begin{array}{c}355.977 \\
2.2810 \times 10^{-4} \\
1.9752 \times 10^{-9} \\
9.2900 \times 10^{-11}\end{array}$ & $\begin{array}{c}355.976 \pm 7.2 \times 10^{-4} \\
2.2812 \times 10^{-4} \pm 8 \times 10^{-8} \\
1.0296 \times 10^{-9} \\
2.6792 \times 10^{-10}\end{array}$ \\
\hline
\end{tabular}

\section{CONCLUSIONS}

The latest generation of metrology devices $(0.05 \mu \mathrm{rad}$ rms accuracy) like the here discussed NOM enables the inspection of a new generation of high accuracy optical elements required in FEL-monochromators. The essential main parameters of the gratings are well within the specifications. A good accordance with the measuring results of the manufacturer can be considered [9] (see also Tabel. 1). Furthermore, the inspection demonstrates the perfect design of the developed mechanical support structure to position the grating in the monochromator. The measured triple VLS-grating represents an optical element of excellent quality characterized by an averaged slope error of less than $0.25 \mu \mathrm{rad}$ rms. This is well beyond the limit of $0.5 \mu \mathrm{rad} \mathrm{rms}$ for optical elements presently in use in SRbeamlines.

\section{ACKNOWLEDGMENTS}

The authors would like to thank Fred Senf (BESSY) and Andreas Seifert (C. ZEISS) for helpful discussions.

\section{REFERENCES}

1. R. Reininger, VLS Grating Efficiencies and Grating Specifications for the Seeded FEL-Beamline, DESY internal report, 2002

2. J. Feldhaus, E.L. Saldin, J.R. Schneider, E.A. Schneidmiller and M.V. Yurkov, Opt. Commun. 140, 341, 1997

3. F. Siewert, T. Noll, T. Schlegel, T. Zeschke and H. Lammert, The Nanometer Optical Component Measuring Machine: a new Sub-nm Topography Measuring Device for X-Ray Optics at BESSY, AIP Conference Proceedings 705, American Institute of Physics, Melville, NY, 2004, pp. 847-550.

4. H. Lammert, T. Noll, T. Schlegel, F. Siewert, T. Zeschke, Patent No: DE 10303659 (28. July 2005)

5. R. Geckeler, Error Minimization in High-Accuracy Scanning Deflectometry, Optics \& Photonics 2006, Proc. of SPIE, to be published

6. F. Siewert, H. Lammert, T. Noll, T. Schlegel, T. Zeschke, T. Hänsel, A. Nickel, A. Schindler, B. Grubert, C. Schlewitt, Advanced metrology, an essential support fort he surface finishing of high performance $x$-ray optics, Optics \& Photonics 2005, Proc. of SPIE Vol. 592101-1, Bellingham, WA, 2005

7. S.C. Irick and W.R. McKinney, Measurement of Diffraction Gratings with a Long Trace Profiler with Application for Synchrotron Beamline Gratings, Synchrotron Radiation Instrumentation, $10^{\text {th }}$ U.S. National Conference, AIP Proceedings, Vol. 417 (June 1997)

8. D. Cocco, G. Sostero, M Zangrando, Technique for measuring the groove density of diffraction gratings using the long trace profiler, REVIEW OF SCIENTIFIC INSTRUMENTS, Volume 74, Number 7, 2003

9. J. Schalk, H. Kirey, Final test report for holographically recorded ion beam etched triple laminar VLS grating on a silicon substrate, Carl Zeiss, Oberkochen, Feb. 2005 